\title{
Optimization of Jirisan Mountain Cudrania tricuspidata leaf substance extraction across solvents and temperatures
}

\author{
Yong Ju Kim ${ }^{1,2^{*}}$ \\ ${ }^{1}$ Department of Herbal Medicine Resources, College of Environmental and Bioresource Sciences, Chonbuk Nà nal University, 79 \\ Gobong-ro, Iksan, Jeollabuk-do, 54596, Republic of Korea \\ ${ }^{2}$ Department of Lifestyle, College of Environmental and Bioresource Sciences, Chonbuk National University, \\ labuk-do, 54596, Republic of Korea

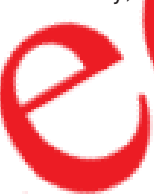 \\ Gobon ro, Iksan, Jeol- \\ .

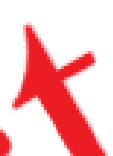 \\ c \\ .
}

Key Words

bioactivity, Cudrania tricuspidata, green extraction ganic solvent

\section{Abstract}

Objective: The mo traction of ber cial su i $m$ Cud ania tricuspidata leaves grouth Korea by three differents ent nending on extraction time and at different tem rature.

Methods: The total $\mathrm{p}$-nolic contents were determined by the method reported by Sánchez-Moreno et al. The total flavonoid contents were analyzed by Slinkard and Singleton. The DPPH radical scavenging activity was determined according to the method reported by Blois

Results: The extraction yield for each solvent is 9.05$14.1 \%, 2.17-5.67 \%$, and $2.3-3.9 \%$ for D.W., ethanol, and hexane, respectively. The overall results were maximized for the extract obtained with D.W. for 5 min at $100^{\circ} \mathrm{C}$. The average phenol contents were 77.11, 45.64, and $0.343 \mathrm{mg} / \mathrm{g}$ at $100^{\circ} \mathrm{C}$ in water, $78^{\circ} \mathrm{C}$ in ethanol, and $68^{\circ} \mathrm{C}$ in hexane, respectively. The flavonoid contents were the in the $m$ ateriais extracted with D.W., and were eas increasing temperature, regardless of the xtraction solvents, whether water (green), polar org ethanol, or nonpolar organic hexane. In the anol extract, the flavonoid contents are increased gradually from $5.66 \mathrm{mg} / \mathrm{g}$ to $7.73 \mathrm{mg} / \mathrm{g}$. The total flavonoid contents were proportional to the concentrations of the water extracts, ranging from $4.14 \mathrm{mg} / \mathrm{g}$ to 48.89 $\mathrm{mg} / \mathrm{g}$. The antioxidative activities of the water-extracted compounds are generally increased with increasing temperature from $42.5 \%$ to $85.5 \%$. Those of the hexane extracts are increased slowly from $3.79 \%$ to $8.8 \%$, while those of ethanol extracts are increased from $29.8 \%$ to $47.4 \%$.

Conclusion: The extraction yields were dependent upon solvents for extraction as well as extraction time and the temperature. The optimal extraction time was $5 \mathrm{~min}$ and the extraction yields were increased with increasing temperature excepted hexane. Of the three tested extraction solvents, the greenest solvent of water shows excellent results, suggesting that water is among the most effective solvents for natural sample extractions for general medicinal, pharmaceutical, and food applications.

\section{Introduction}

"Corresponding Author

Department of Lifestyle, College of Environmental and Bioresource Sciences, Chonbuk National University, 79 Gobong-ro, Iksan, Jeollabuk-do, 54596, Republic of Korea E-mail: nationface@jbnu.ac.kr Phone: +82-630850-0745, Fax: +82-63-850-0741 
Cudrania tricuspidata is a plant of the Moraceae family native to Korea, Japan, and China that often grows at the foot of mountains. Approximately ten kinds of Cudrania tricuspidata are known. The fruit is used in jams and alcoholic beverages, bark and roots are used for medicine, and leaves are used in teas and soups as substitutes for mulberry leaves. Cudrania tricuspidata has traditionally been used as a medicinal plant for conditions including eczema, tuberculosis, and chronic back pain [1]. According to previous studies, the plant has many beneficial characteristics, including antioxidative [2], antimicrobial [3], antitumor [4], antiobesity [5], anti-osteoarthritis [6], antiaging [7], antiinflammatory, and neuroprotective [8] properties. It also shows efficacy against cardiovascular diseases [9] such as atherosclerosis and hypertension [10].

Although organic solvents must be used to extract some natural materials, despite their potential hazards and generation of toxic substances, environmentally and biologically friendly "green" extraction technologies for natural substances are developing rapidly in the medicinal, pharmaceutical, and food industries [11-13]. Water is the greenest solvent; it is nontoxic to the human body, environmentally friendly, and safe to work with, and is therefore considered among the most environmentally sustainable solvents [14]. Water extraction temperatures can be varied to increase the extracted quantity of effective beneficial substances from natural sources. Moreover, high-temperature water extraction (HTWE) can shorten the extrac n time. However, a precise understanding of the st? ty of natural extracts at various temperatures a time c hitions is necessary for implementing HTWE. his stu is intended not to characterize the benen $1 \mathrm{ch}$ nical si stances of Cudranian spidata eaves (CTL), t $\mathrm{o}$ determine the mal ex ction o nditions for obtaining beneficial subst es wi loptimize dative effects, total phenolic col flavonoid contents using the different extraction lvents on ethanol, and hexane.

\section{Materials and Methods}

\section{Materials and Methods}

\section{Materials}

Cudrania tricuspidata leaves (CTL) used were collected in April and May of 2017 by a medicinal plant supplier from Jirisan Mountain in Sancheong County, Gyeongnam, South Korea.

\section{Extraction from CTL}

$10 \mathrm{~g}$ of dried and ground CTL were mixed with $100 \mathrm{~mL}$ of distilled water (D.W.), $100 \mathrm{~mL}$ ethanol, or $100 \mathrm{~mL}$ hexane, respectively. The extraction was performed for time intervals of $5 \mathrm{~min}, 15 \mathrm{~min}, 30 \mathrm{~min}, 45 \mathrm{~min}$, and $1 \mathrm{~h}$. The temperature of the water extraction was varied from room temperature (RT) to $40^{\circ} \mathrm{C}, 60^{\circ} \mathrm{C}, 80^{\circ} \mathrm{C}$, and $100^{\circ} \mathrm{C}$. Ethanol extractions were performed at RT, $40^{\circ} \mathrm{C}, 60^{\circ} \mathrm{C}$, and $78^{\circ} \mathrm{C}$, while hexane extractions were performed at RT, $40^{\circ} \mathrm{C}$, and $68^{\circ} \mathrm{C}$. Heat-reflux extraction using a water-bath was performed to maintain the extraction temperature. All extracts were filtered with Whatman ${ }^{\bullet}$ Grade 2 qualitative filter papers (GE Healthcare), evaporated, and dried using a freezing dryer (FD5508, Ilshin Lab Co., Ltd.) before use.

\section{Functional bioassays of CTL}

For the functional bioassays, 1-mL samples of the extracts were centrifuged at $8000 \mathrm{rpm}$ for $5 \mathrm{~min}$ and then filtered with a syringe filter (Hyundae, $0.45 \mu \mathrm{m}$ ). The total phenolic contents were determined by the method reported by Sánchez-Moreno et al. $[15,16]$ from the standard curve prepared using garlic acid as a standard. The total flavonoid contents were analyzed by the standard curve using catechin, as described by Slinkard and Singleton $[17,18]$. The DPPH radical scavenging activity was determined according to the method reported by Blois $[16,19]$.

\section{Statistical Analysis}

All experiments were independently ormed in triplicate $(n=3)$ to obtain statistic valu s. The ata reported are expressed as the mean + ctanda deviat One-way analysis of variance was asea, or istical, nificance $(\mathrm{p}<0.05)$.

\section{Res flts and D cyssion}

M y be ficial abstances supporting human health have bee xtracuu and analyzed both chemically and structurally f natural sources. Scientific efforts to discover new tances remain active (Table 1 and Table S1).

The three different extraction solvents of distilled water (D.W.), ethanol, and hexane were analyzed in terms of yield rates. The extraction yield for each solvent is represented in Fig. 1a, at 9.05-14.1\%, 2.17-5.67\%, and 2.3-3.9\% for D.W., ethanol, and hexane, respectively. The extraction yield of D.W. was increased as the temperature increased, maximizing at $100^{\circ} \mathrm{C}$. Ethanol and hexane yields were also increased with temperature and time. For hexane, yield was increased at room temperature, but decreased at $40^{\circ} \mathrm{C}$ and $68^{\circ} \mathrm{C}$ (Table S2). The overall results were maximized for the extract obtained with D.W. for $5 \mathrm{~min}$ at $100^{\circ} \mathrm{C}$. Functional bioassays according to concentration were also performed on extracts with D.W. for $5 \mathrm{~min}$ at $100^{\circ} \mathrm{C}$. As the concentrations of the samples were increased, the bioactivities also increased (Table S3). Although the extraction yield with D.W. was decreased when $20 \mathrm{~g}$ of dried and ground CTL were extracted using $100 \mathrm{~mL}$ solvent, the bioactivities were slightly increased. From the preliminary optimization of extraction yield with each solvent, $10 \mathrm{~g}$ of dried and ground CTL in $100 \mathrm{~mL}$ solvent showed the best results; these quantities were thus maintained for all later extraction experiments (Fig. 1b).

The polyphenol compounds in plants are important because of their hydroxyl group-related scavenging abilities, which facilitate binding with various compounds and grant antioxidative, anticarcinogenic, and antiinflammatory properties [20]. The polyphenol contents were analyzed based on the extraction solvents, temperatures, and times (Fig. 2a). Regarding the solvent used, D.W. yielded significantly higher phenol contents than ethanol and hexane did. For extraction temperature, the amount of ex- 
tracted phenol increased as the temperature was increased. The average phenol contents were $77.11,45.64$, and 0.343 $\mathrm{mg} / \mathrm{g}$ at $100^{\circ} \mathrm{C}$ in water, $78^{\circ} \mathrm{C}$ in ethanol, and $68^{\circ} \mathrm{C}$ in hexane, respectively. As the extraction time was extended, the phenol contents slightly decreased from $80.21 \mathrm{mg} / \mathrm{g}$ to $73.97 \mathrm{mg} / \mathrm{g}$ in water, but this difference was insignificant. In ethanol and hexane, the phenol contents slightly increased with time extension, from 43.64 to $46.59 \mathrm{mg}$ and from 0.288 to $0.4 \mathrm{mg}$, respectively (Table S4). The total phenolic compounds gradually increased from $30.32 \mathrm{mg} / \mathrm{g}$ to $79.2 \mathrm{mg} / \mathrm{g}$ by increasing the quantities of extract in D.W.

Flavonoids are a subset of polyphenols and are widely distributed in natural materials. They have high antioxidative activities, effectively eliminating reactive oxygen species, in addition to antiviral, antiinflammatory, and anticancer functions [21]. The flavonoid contents were the highest in the materials extracted with D.W., and were increased with increasing temperature, regardless of the extraction solvents, whether water (green), polar organic ethanol, or nonpolar organic hexane. In the ethanol extract, the flavonoid contents are increased gradually from $5.66 \mathrm{mg} / \mathrm{g}$ to $7.73 \mathrm{mg} / \mathrm{g}$ (Fig. 2b). The total flavonoid contents were proportional to the concentrations of the water extracts, ranging from $4.14 \mathrm{mg} / \mathrm{g}$ to $48.89 \mathrm{mg} / \mathrm{g}$ (Table S5).

1,1-Diphenyl-2-dipicryldihydrazyl (DPPH) is a stable free radical that is reduced by antioxidant compounds, and thus is used to measure antioxidative activity [22]. The antioxidative activities of the water-extracted compounds are generally increased with increasing temperature from $42.5 \%$ to $85.5 \%$ (Fig. 2c). Those of the hexane extracts are increased slowly from $3.79 \%$ to $8.8 \%$, while those thanol extracts are increased from $29.8 \%$ to $\%$. De ite the lower quantities, the hexane extrantomay ow dif ent properties than the water or et rano xtrac becaus of the nonpolar ature the sol enl. The tota ioxidative activitfes the w r-extra ed com ounds were much higher tha hose of ethanol xane. The antioxidant activities the were steadily increased with increasing sam mass, whe the exception of samples exceeding $10 \mathrm{~g}(\mathrm{~T}$, e S6).

\section{Conclusion}

This study systematically investigated changes in functionality, such as the total contents of polyphenols and flavonoids and the antioxidant activities, of CTL extracts when obtained using different extraction solvents, temperatures, and times. Water extraction yielded compounds showing not only significantly higher total contents of polyphenols and flavonoids, but also greater antioxidant activities, than extraction by organic polar or nonpolar solvents. The optimal extraction time was $5 \mathrm{~min}$ and the extraction yields were increased with increasing temperature, however hexane was the exception. Of the three tested extraction solvents, the greenest solvent of water shows excellent results, suggesting that water is among the most effective solvents for natural sample extractions for general medicinal, pharmaceutical, and food applications.

\section{Conflict of interest}

The authors declars that he has no conflict of interests

\section{Acknowledgements}

I thank Chair Prof. Dr. Hui-Woog Choe at Chonbuk National University and at the Department of Brain \& Cognitive Sciences of DGIST, Republic of Korea, for fruitful discussions and continuous support of this work. I also thank Prof. Dr. Keug Soo Bang for giving me strong motivation and support for this work. This work was supported by the Basic Science Research Program through the National Research Foundation of Korea (NRF), the Ministry of Science, ICT \& Future Planning (2015R1C1A1A02037509).

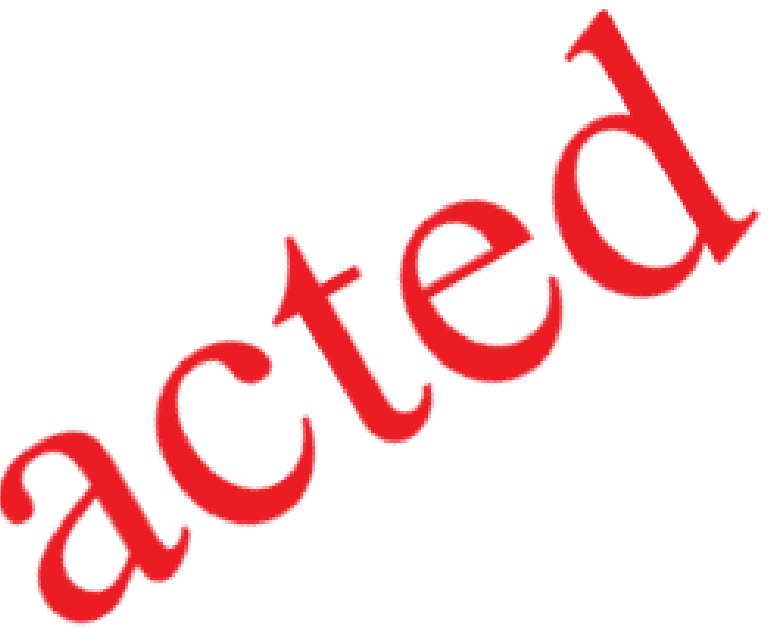


Table 1 Total phenols, flavonoids concentration and antioxidant activity of plant extracts.

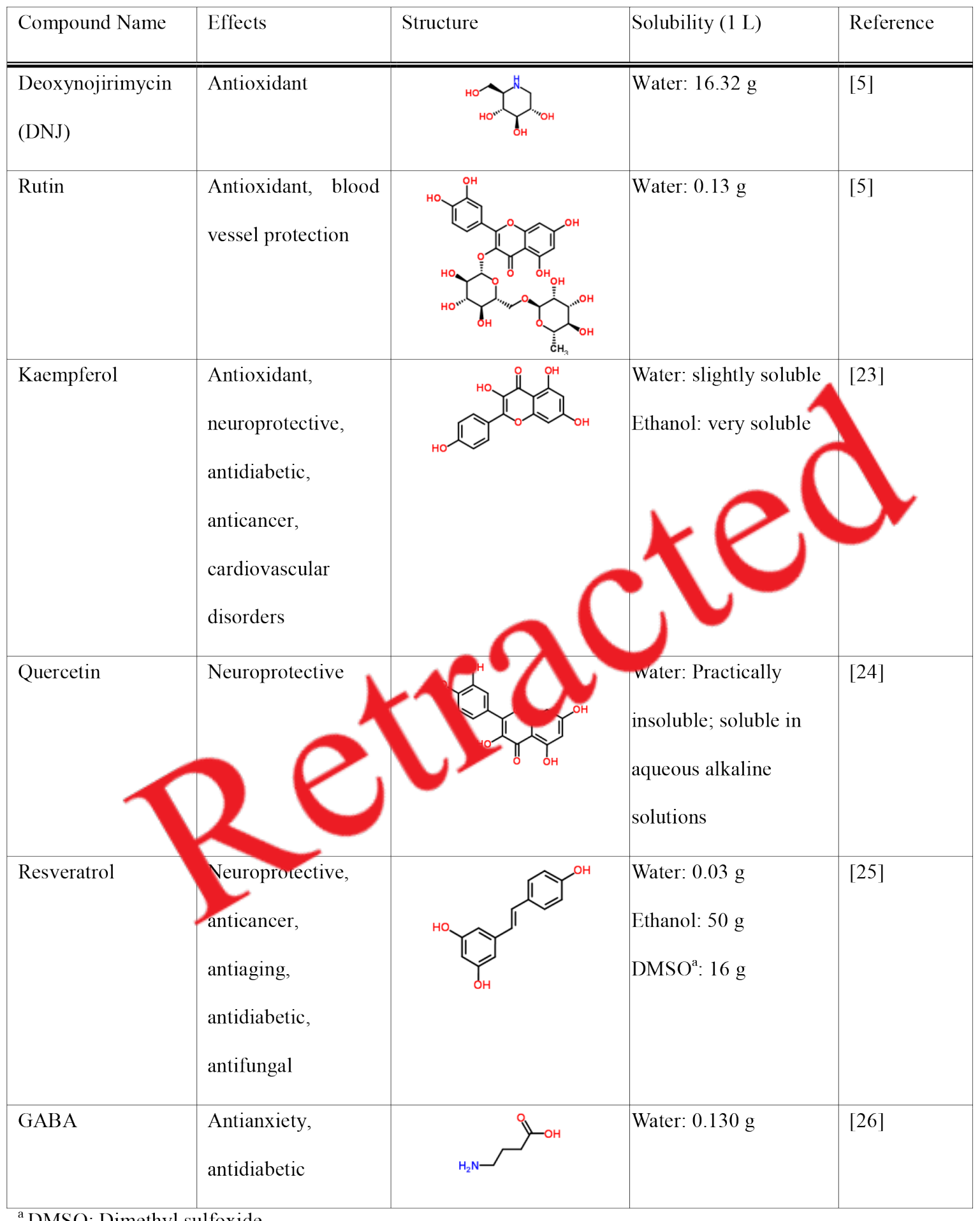

\footnotetext{
${ }^{a}$ DMSO: Dimethyl sulfoxide
} 
Table 1 Total phenols, flavonoids concentration and antioxidant activity of plant extracts.

\begin{tabular}{|c|c|c|c|}
\hline Compound name & Effects & Structure & Reference \\
\hline Myricetin & Neuroprotective & & [1] \\
\hline Oxyresveratrol & $\begin{array}{l}\text { Skin protection, } \\
\text { hepatoprotective }\end{array}$ & & \\
\hline Cudratricusxanthone A & $\begin{array}{l}\text { Antiplatelet, } \\
\text { anticoagulant }\end{array}$ & & [3] \\
\hline Macluraxanthone B & & & [3] \\
\hline Imperatori & $\begin{array}{l}\text { Anticonvulsant, } \\
\text { anticancer }\end{array}$ & & [4] \\
\hline Isoimperatorin & $\begin{array}{l}\text { Antiinflammatory, } \\
\text { hepatoprotective effect, } \\
\text { antimycobacterial activity }\end{array}$ & & [4] \\
\hline
\end{tabular}




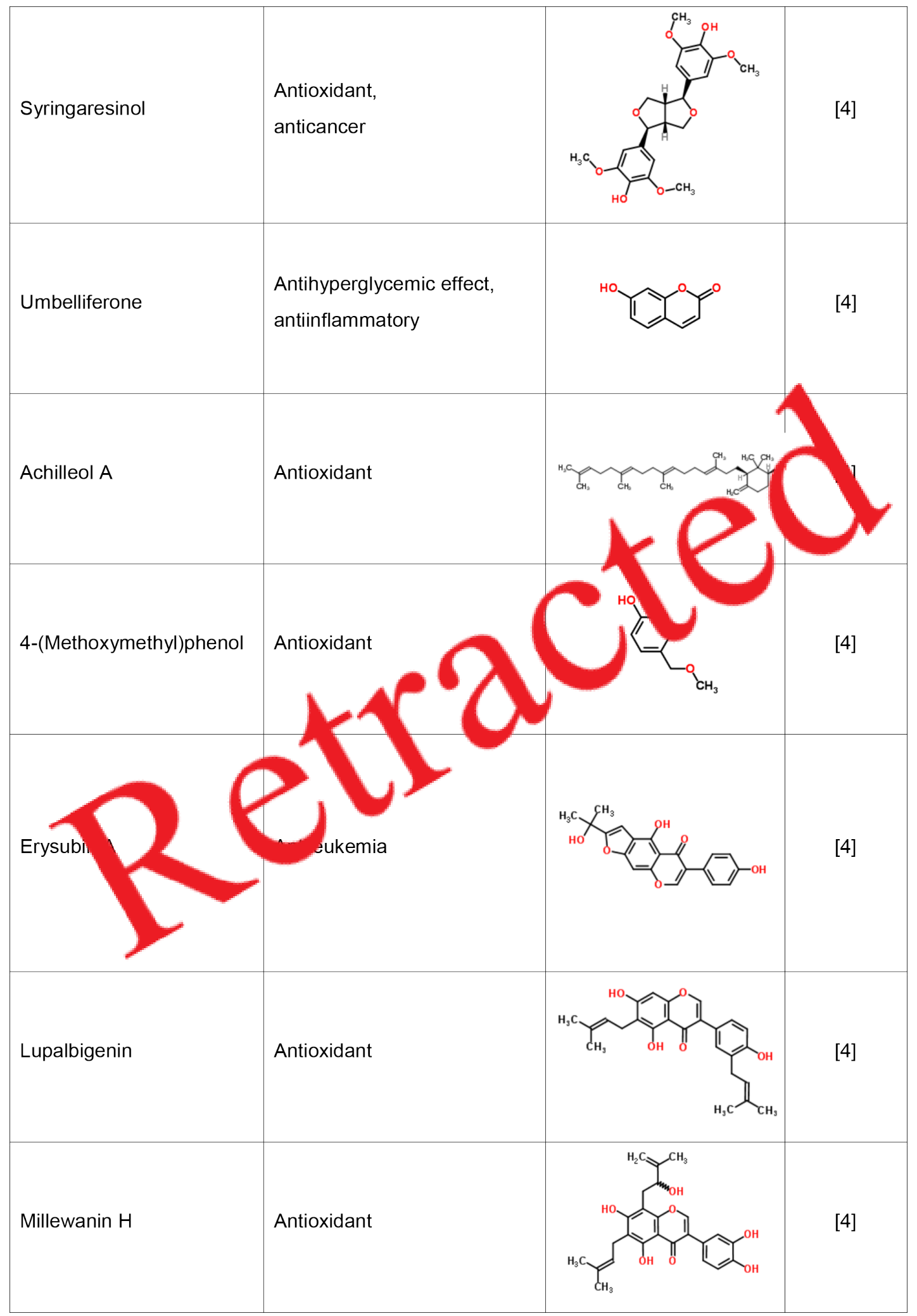




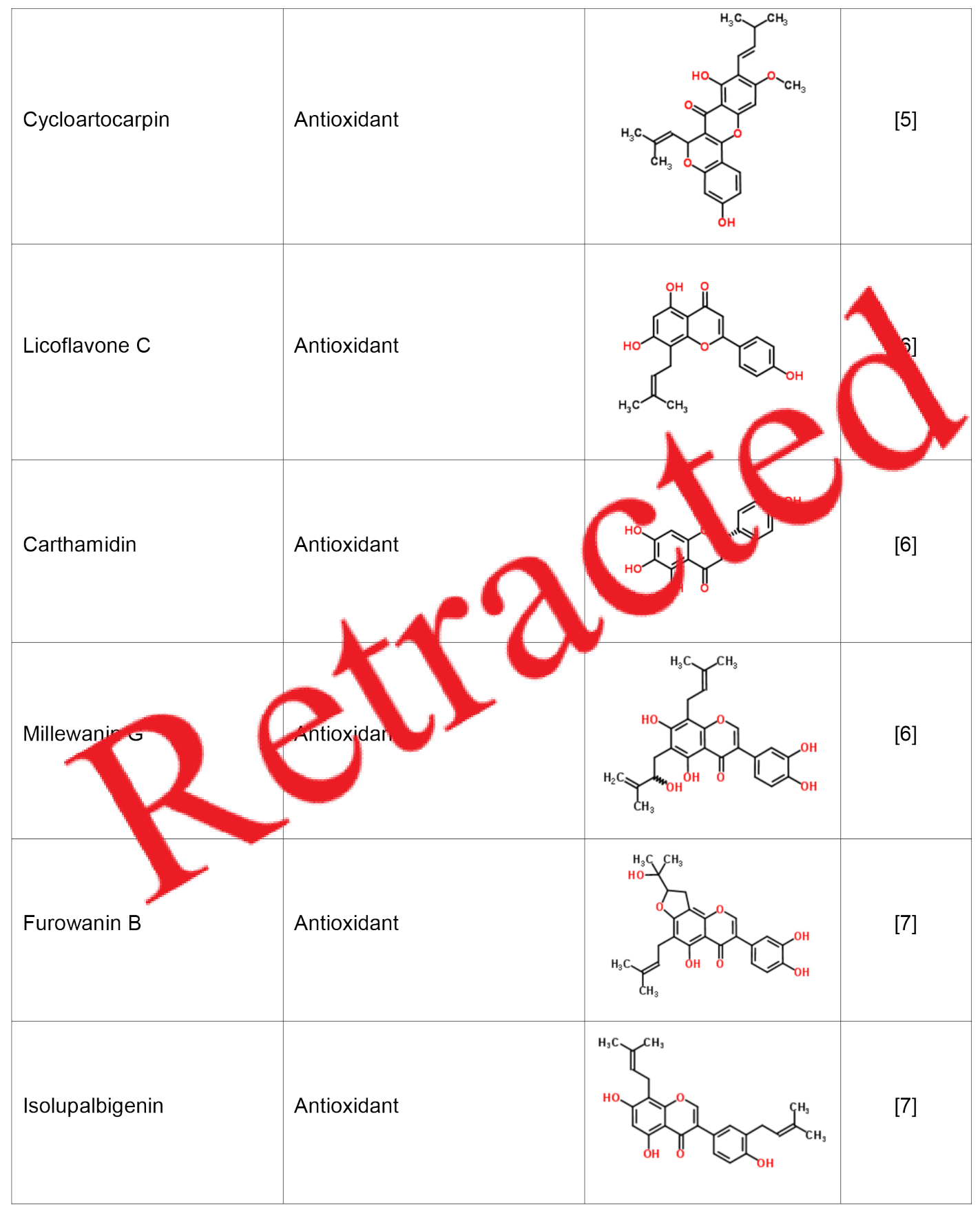


Table S2 The extraction yield by three different solvents

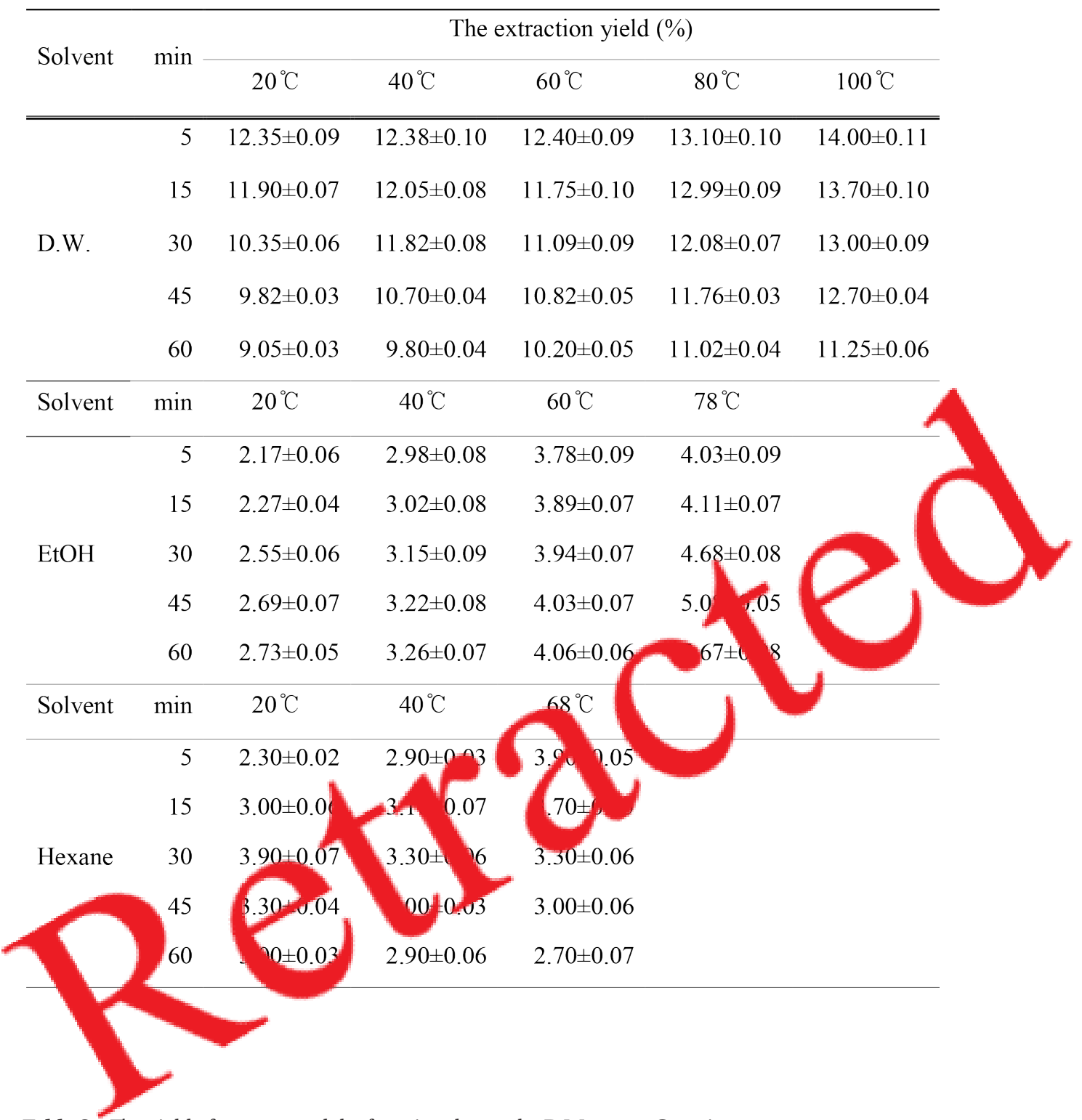

Table S3 The yield of extracts and the functional assay by D.W. at $100^{\circ} \mathrm{C}, 5 \mathrm{~min}$

\begin{tabular}{lccccc}
\hline & $\mathbf{1 g}$ & $\mathbf{2 . 5 g}$ & $\mathbf{5 g}$ & $\mathbf{1 0 g}$ & $\mathbf{2 0 ~ g}$ \\
\cline { 2 - 6 } & $2.88 \pm 0.02$ & $6.30 \pm 0.04$ & $11.10 \pm 0.03$ & $14.10 \pm 0.05$ & $6.52 \pm 0.03$ \\
\hline \hline The yield (\%) & & & & \\
\hline Phenolic (mg/g) & $30.32 \pm 0.09$ & $36.00 \pm 0.08$ & $54.00 \pm 0.06$ & $69.60 \pm 0.03$ & $79.2 \pm 0.07$ \\
\hline Flavonoid & & & & & \\
(mg/g) & $4.14 \pm 0.07$ & $10.84 \pm 0.09$ & $22.60 \pm 0.05$ & $42.47 \pm 0.05$ & $48.89 \pm 0.05$ \\
\hline DPPH (\%) & $18.19 \pm 0.06$ & $26.70 \pm 0.04$ & $41.32 \pm 0.07$ & $70.76 \pm 0.08$ & $78.44 \pm 0.09$ \\
\hline
\end{tabular}


Table S4 The total phenolic by three different solvents

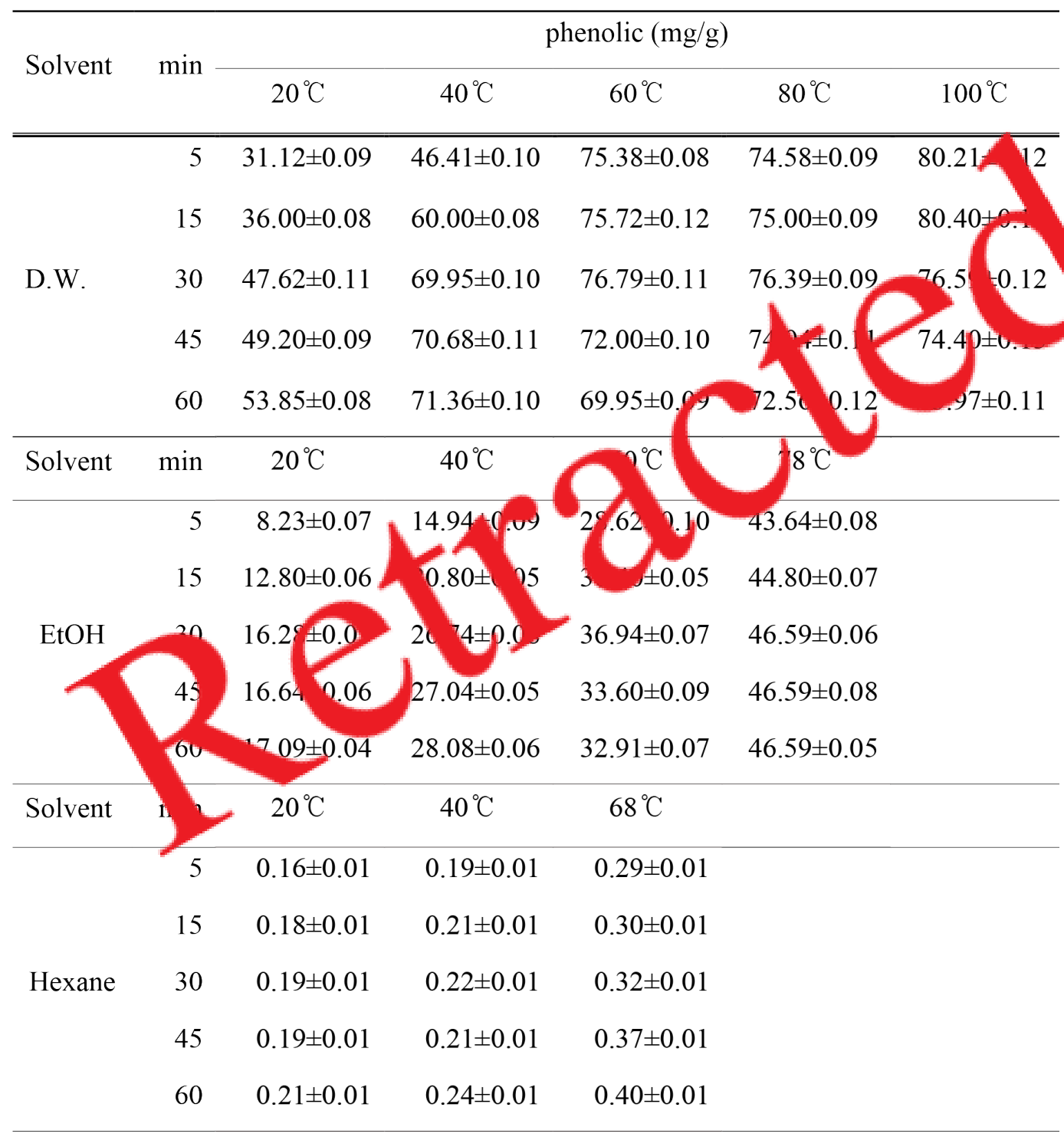


Table S5 The total flavonoid by three different solvents

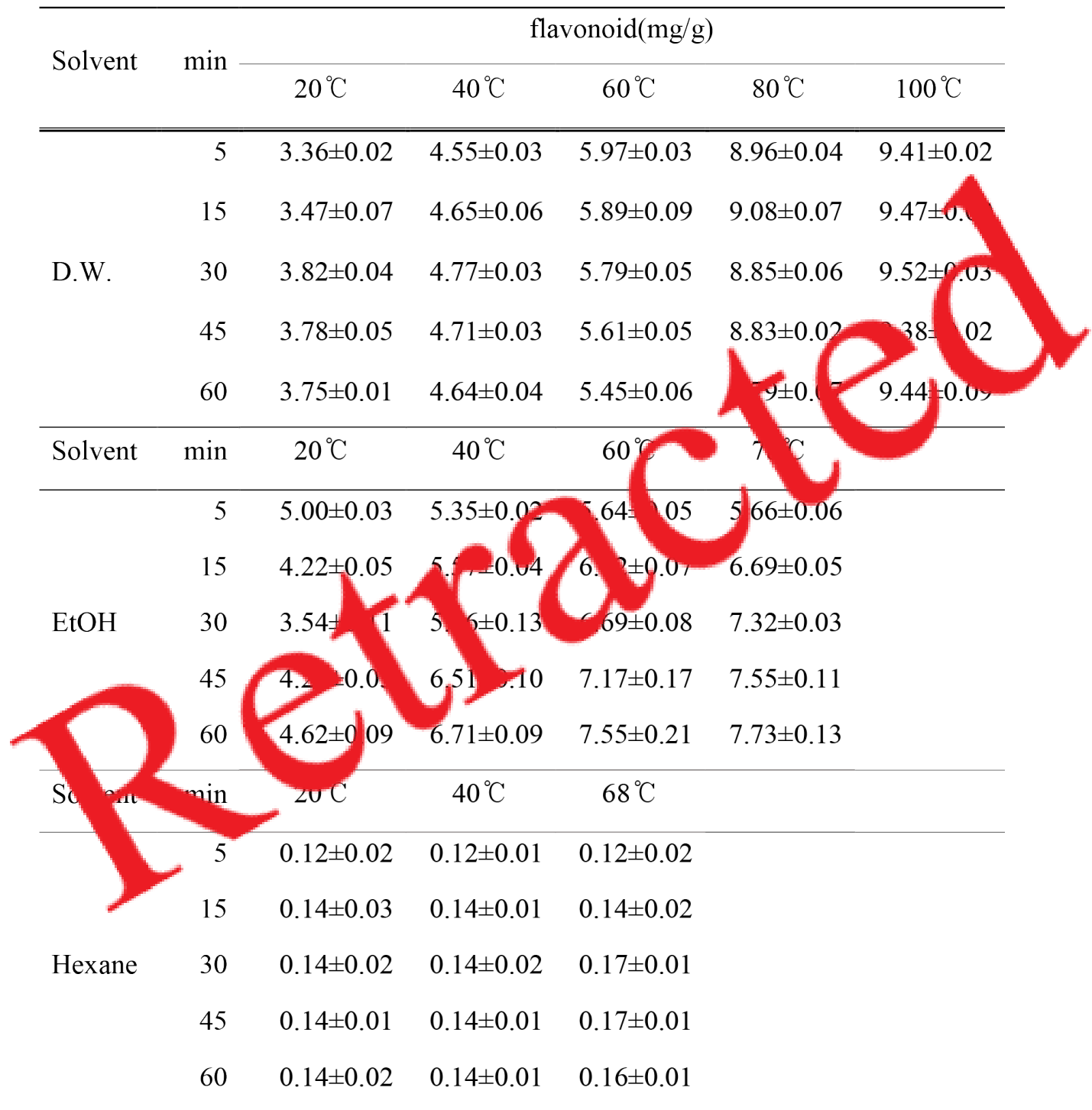


Table S6 The effect of extracts condition on DPPH radical scavenging activity by three different solvents

\begin{tabular}{|c|c|c|c|c|c|c|}
\hline \multirow{2}{*}{ Solvent } & \multirow{2}{*}{$\min$} & \multicolumn{5}{|c|}{ DPPH $(\%)$} \\
\hline & & $20^{\circ} \mathrm{C}$ & $40^{\circ} \mathrm{C}$ & $60^{\circ} \mathrm{C}$ & $80^{\circ} \mathrm{C}$ & $100^{\circ} \mathrm{C}$ \\
\hline \multirow{5}{*}{ D.W. } & 5 & $42.50 \pm 0.06$ & $55.30 \pm 0.10$ & $68.20 \pm 0.11$ & $78.00 \pm 0.10$ & $85.50 \pm 0.09$ \\
\hline & 15 & $48.00 \pm 0.10$ & $56.20 \pm 0.10$ & $69.80 \pm 0.07$ & $79.00 \pm 0.06$ & $85.00 \pm 0.10$ \\
\hline & 30 & $50.60 \pm 0.08$ & $57.10 \pm 0.07$ & $66.80 \pm 0.11$ & $80.70 \pm 0.09$ & \\
\hline & 45 & $50.90 \pm 0.09$ & $55.00 \pm 0.08$ & $64.00 \pm 0.10$ & $78.00 \pm 0.07$ & \\
\hline & 60 & $51.20 \pm 0.10$ & $53.70 \pm 0.11$ & $61.00 \pm 0.10$ & & \\
\hline \multirow[t]{3}{*}{ Solvent } & $\min$ & $20^{\circ} \mathrm{C}$ & $40^{\circ} \mathrm{C}$ & $60^{\circ} \mathrm{C}$ & & \\
\hline & 5 & $29.80 \pm 0.10$ & $35.90 \pm 0.10$ & & & \\
\hline & 15 & $30.00 \pm 0.08$ & & & $48.00 \pm 0.09$ & \\
\hline \multirow[t]{6}{*}{$\mathrm{EtOH}$} & 30 & & & & $49.50 \pm 0.11$ & \\
\hline & 45 & & & $49.50 \pm 0.10$ & $53.50 \pm 0.10$ & \\
\hline & & & & $51.60 \pm 0.07$ & $57.50 \pm 0.08$ & \\
\hline & & & $40^{\circ} \mathrm{C}$ & $68^{\circ} \mathrm{C}$ & & \\
\hline & & 0.03 & $7.42 \pm 0.05$ & $8.80 \pm 0.02$ & & \\
\hline & & $2.75 \pm 0.03$ & $8.42 \pm 0.02$ & $9.60 \pm 0.04$ & & \\
\hline \multirow[t]{3}{*}{ Hexane } & 30 & $2.21 \pm 0.02$ & $8.22 \pm 0.04$ & $10.15 \pm 0.03$ & & \\
\hline & 45 & $2.00 \pm 0.01$ & $8.09 \pm 0.01$ & $9.60 \pm 0.01$ & & \\
\hline & 60 & $1.97 \pm 0.02$ & $8.02 \pm 0.03$ & $9.20 \pm 0.02$ & & \\
\hline
\end{tabular}



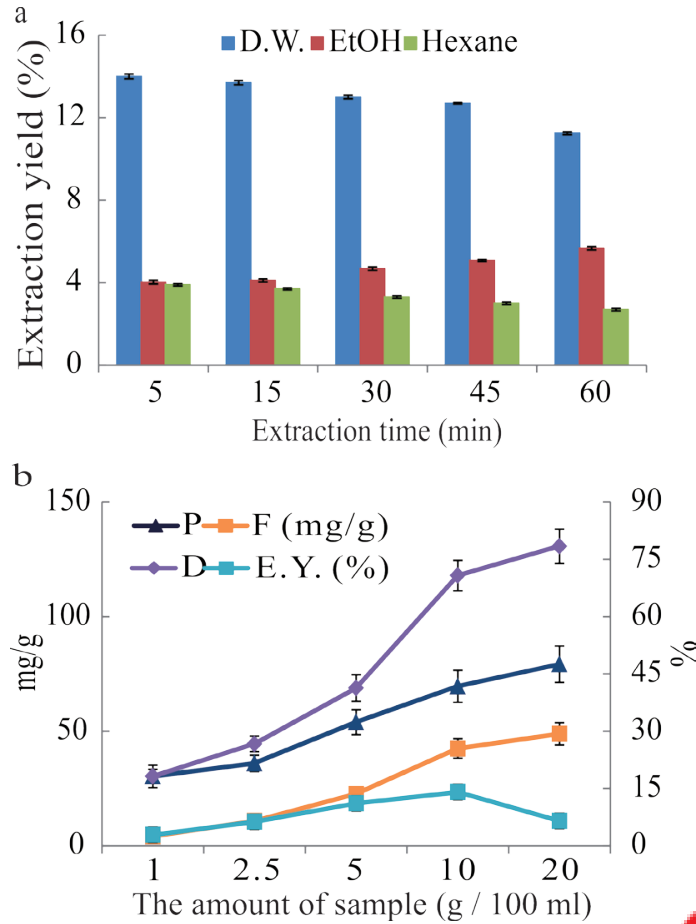

Figure 1 The yields of CTL extract. a. Extr ion yiel by D.W., ethanol (EtOH), and boxa. b. I yield o, D.W. extracts 2 ctional a say b. D.W.
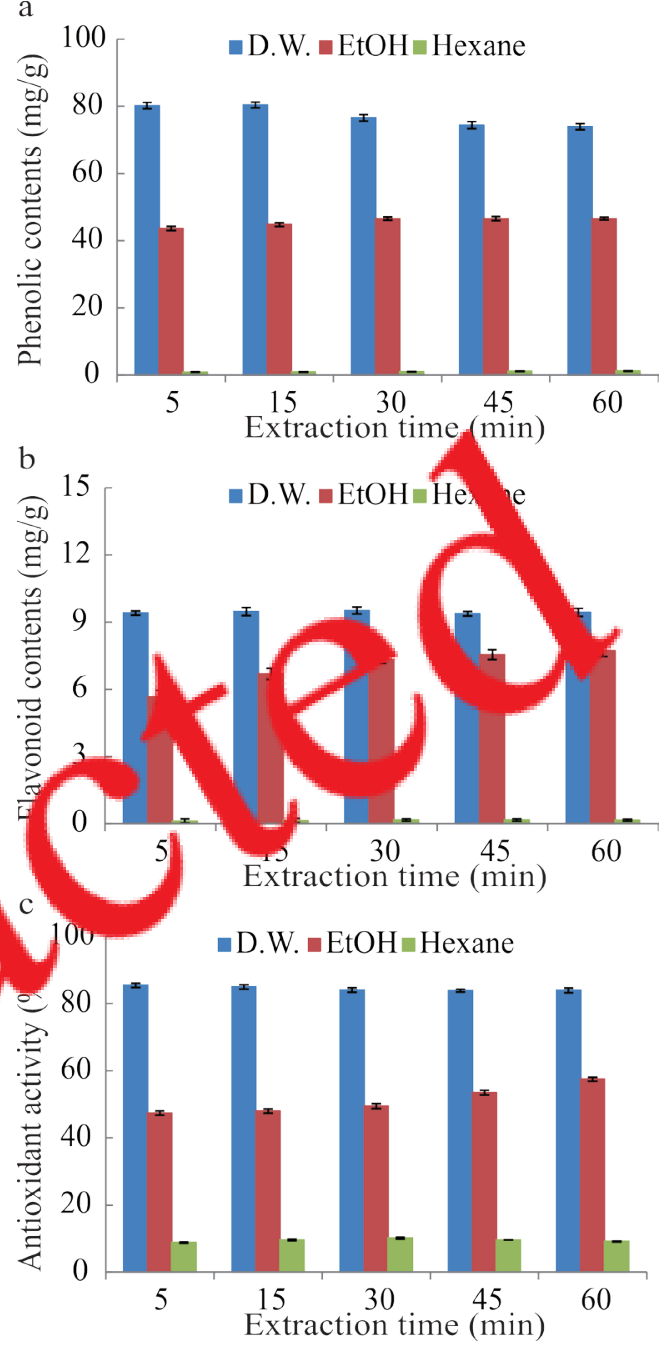

Figure 2 Total polyphenol contents of CTL by three different extraction conditions. a. The estimation of total polyphenol contents in extracts by three different solvents. b. The estimation of total flavonoid contents in extracts by three different solvents. c. The effects of extraction conditions on the DPPH radical scavenging activities of the CTL extracts. 


\section{References}

1. Lee BW, Lee J H, Lee ST, Lee HS, Lee WS, Jeong TS, et al. Antioxidant and cytotoxic activities of xanthones from Cudrania tricuspidata. Bioorganic \& medicinal chemistry letters, 2005. 15(24): p. 5548-5552

2. Lee JH, Lee BW, Kim JH, Seo WD, Jang KC, Park KH (2005) Antioxidant effects of isoflavones from the stem bark of Cudrania tricuspidata. Journal of Applied Biological Chemistry 48(4):193-197.

3. Choi SR, You DH, Kim JY, Park CB, Kim DH, Ryu J, et al. ]Antimicrobial activity of methanol extracts from Cudrania tricuspidata Bureau according to the parts harvested and time]. Korean Journal of Medicinal Crop Science, 2009. 17(5): p. 335-340.

4. Kim M, Kim IA, Ko YJ, Jeong JA, Kim JE, Song BJ, et al., [Methanol extract of leaves from Cudrania tricuspidata effects in HT-29 colorectal adenocarcinoma]. Korean J Oral maxillofac Pathol, 2009. 33: p. 19-26.

5. Do GP, Lee HJ, Do JR, Kim HK. [Inhibition of Adipogenesis in 3T3-Ll Adipocytes with Water and Ethanol Extracts of Cudrania tricuspidata Leaves[. Korean Journal of Food Preservation, 2011. 18(2): p. 244-249.

6. Nam DE, Kim OK, Lee J. [Therapeutic effects of Curdrania tricuspidata leaf extract on osteoarthritis]. Journal of the Korean Society of Food Science and Nutrition, 2013. 42(5): p. 697-704.

7. Han HS, Kim SY, Lim DJ, Whang WK. [Development of whitening cosmetic ingredients from Cudrania tricuspidata stem extract]. Asian Journal of Beauty and Cosmetology, 2016. 14(3): p. 317-328.

8. Park JH, Lee KW, Sung KS, Kim SS, Cho D Lee I, et al., [Effect of diets with mulberry leaf an, udrani ricuspidata leaf powder supplementann blo glucos related biomarkerc in streptozc ocin rduce diabe rats]. Journal then an Soc ty of Food Sci and Nutrition, 2 .41(6) 766-77

9. Park KH, Pan D, H n JM, Im K BW, Jeong IY, et al. Anti-ath and anti-inflammatory activities of catech xanthow and flavonoids isolated from Cudrania th spidata. Bioorganic \& medicinal chemistry letters, 2 o. 16(21):5580-5583.

10. Kang DG, Hur TY, Lee GM, Oh H, Kwon TO, Sohn EJ, et al. Effects of Cudrania tricuspidata water extract on blood pressure and renal functions in NO-dependent hypertension. Life Sciences, 2002. 70(22):2599-2609.

11. Bart HJ Extraction of Natural Products from Plants - An Introduction. In: Industrial Scale Natural Products Extraction. Wiley-VCH Verlag GmbH \& Co. KGaA; 2001. 1-25.

12. Grodowska K, Parczewski A. Organic solvents in the pharmaceutical industry. Acta Pol Pharm, 2010. 67(1):3-12.

13. kumar S S, D S. Health Hazards of Organic Solvents. Research and Reviews Journal of Chemistry, 2015. 4(2):9095.

14. Castro-Puyana M, Marina ML, Plaza M. Water as green extraction solvent: Principles and reasons for its use. Current Opinion in Green and Sustainable Chemistry, 2017. 5:31-36.

15. Sánchez-Moreno C, Cao G, Ou B, Prior RL. Anthocy- anin and proanthocyanidin content in selected white and red wines. Oxygen radical absorbance capacity comparison with nontraditional wines obtained from highbush blueberry. Journal of Agricultural and Food Chemistry, 2003. 51(17):4889-4896.

16. Lee H-J, Do J-R, Kwon J-H, Kim H-K. [Physiological activities of extracts from different parts of Cudrania tricuspidata]. Journal of the Korean Society of Food Science and Nutrition, 2011. 40(7):942-948.

17. Slinkard K, Singleton VL. Total phenol analysis: automation and comparison with manual methods. American journal of enology and viticulture 28(1):49-55.

18. Park H-M, Hong J-H (2014) [Effect of extraction methods on antioxidant activities of Mori ramulus]. Journal of the Korean Society of Food Science and Nutrition, 1977. 43(11):1709-1715.

19. Blois MS. Antioxidant determinations by the use of a stable free radical. Nature, 1958.181 17):1199-1200

20. Lu Y, Yeap Foo L. Antioxidant and ra cal scavenging activities of polyphenols from apple mace. Food Chemistry, 2000. 68(1):81-85.

21. Tsao R. Chemistry and Bioch mistry f Dietary Polyphenols. Nutrients, 2014 12) 231-124

22. David J, Barre os A, I avid, Antic Jant Phenylpropanoid Esters Triter nes fron Diocrea lasiophylla. Pharmaceutical logy, nu 1 ):36-38.

23. Calde on-Muntanc M, Burguo-Moron E, Perez-Guerrero C, opez-Lazaro $A$ review on the dietary flavonoid aem erol. Mir Rev Med Chem, 2011. 11(4):298-344.

24. alil man SA. The Potential Role of Honey an its Poryphenols in Preventing Heart Diseases: A Re v. African Journal of Traditional, Complementaand Alternative Medicines, 2010. 7(4):315-321.

25. Kim HB, Kim JB, Kim SL. [Varietal Analysis and Quantification of Resveratrol in Mulberry Fruits[, 2005. 47(2): 51-55

26. Kim H, Kim H, Jun B, Cha J, Kim H, Cho Y. [Analysis of $\gamma$-aminobutyric acid concentrations in Korean plants and mushrooms[. J Life Sci, 2011. 11:537-542 